CLINICAL STUDY

\title{
Body iron stores and the risk of type 2 diabetes in middle-aged men
}

\author{
Alex Aregbesola, Sari Voutilainen, Jyrki K Virtanen, Jaakko Mursu and Tomi-Pekka Tuomainen \\ Institute of Public Health and Clinical Nutrition, University of Eastern Finland, Yliopistonranta 1C, PO Box 1627, FI70211 Kuopio, Finland \\ (Correspondence should be addressed to A Aregbesola; Email: alex.aregbesola@uef.fi)
}

\begin{abstract}
Objective: We investigated the risk of type 2 diabetes mellitus (T2DM) over a wide range of body iron stores.

Methods: Prospective cohort of 1613 men in the Kuopio Ischemic Heart Disease Risk Factor study, aged 42-60 years, free of T2DM and hereditary hemochromatosis at baseline in 1984-1989. Baseline serum ferritin (sF) and serum-soluble transferrin receptor (sTfR) concentrations were used to predict incident T2DM. T2DM was assessed by questionnaires, blood glucose measurements, and medication reimbursement register.

Results: There were 331 cases of incident T2DM during the mean follow-up of 16.8 years (27098 person-years). At baseline, subjects who later developed T2DM had average sF concentrations of $191 \mu \mathrm{g} / \mathrm{l}$ (S.D. 155) vs $151 \mu \mathrm{g} / \mathrm{l}$ (s.D. 119) among those who remained healthy, $P<0.001$. In a multivariate-adjusted logistic regression, each $100 \mu \mathrm{g} / \mathrm{l}$ increase in sF corresponded to an average of $14 \%$ increased (odds ratio $=1.14,95 \%$ CI $1.03-1.26, P=0.009$ ) risk of developing T2DM. In a Cox regression, a markedly increased risk of developing T2DM was observed from the fourth sF quintile $(185 \mu \mathrm{g} / \mathrm{l}$, the median) upward (hazard ratio (HR) first vs fifth quintile $=1.5,95 \%$ CI $1.0-2.2$, $P$-trend $=0.05)$. In a corresponding Cox model in sTfR, the subjects in the third quintile $(1840 \mu \mathrm{g} / \mathrm{l}$, the median) had the least risk $(\mathrm{HR}=0.63,95 \% \mathrm{CI} 0.42-0.97, P=0.04)$.

Conclusions: Body iron within the $\mathrm{sF}$ reference range is not an important determinant of T2DM risk, whereas high normal and above is associated with markedly increased risk. Iron depletion toward iron deficiency as assessed by STfR is not protective against T2DM. A rule of thumb safe range could be $30-200 \mu \mathrm{g} / \mathrm{l}$ of $\mathrm{sF}$.
\end{abstract}

European Journal of Endocrinology 169 247-253

\section{Introduction}

Impaired glucose homeostasis, mainly due to $\beta$-cell dysfunction, and the later progression to type 2 diabetes mellitus (T2DM) in the iron accumulation disorder hereditary hemochromatosis are well documented (1). Several etiological pathways from iron-induced oxidative damage $(2,3)$ to impaired insulin sensitivity and increased insulin resistance $(4,5,6,7,8)$, have been suggested in iron-T2DM hypothesis. Despite the fact that ferritin is an acute-phase reactant that may be elevated in the presence of liver disease, inflammation, and neoplasm, it has been predominantly used as a marker of body iron stores especially in epidemiological studies $(9,10)$. Serum-soluble transferrin receptor (sTfR) is the soluble fragment of the transferrin receptor domain (a membrane glycoprotein) and it is elevated in expanded or inefficient erythropoiesis such as in iron deficiency (11).

Several observational studies $(10,12,13,14,15$, 16), a lifestyle intervention study (17) and a placebo arm of a randomized controlled trial (18) have examined the association between mildly elevated body iron stores and T2DM with no clear-cut range within which the body iron stores should be maintained. A recent meta-analysis of relevant studies addressing this study question further provided supportive evidence base for mildly elevated body iron stores as a risk factor of T2DM but also did not report the ideal range (19).

Thus, we decided to investigate the risk of T2DM over a wide range of body iron stores, as assessed by serum ferritin (sF), and whether iron depletion toward mild iron deficiency, as assessed by sTfR, offers protection against T2DM.

\section{Subjects and methods}

\section{Study population}

The Kuopio Ischemic Heart Disease Risk Factor (KIHD) study is an ongoing prospective population-based study designed to investigate the risk factors for 
cardiovascular disease, atherosclerosis, and other chronic diseases in middle-aged men from Kuopio and the surrounding communities in eastern Finland (20). The baseline examinations were carried out in 1984-1989, with a random sample of men living in the city of Kuopio and its environs. A total of 2682 men ( $83 \%$ of the eligible) in the four age strata, $42,48,54$, or 60 years old at baseline, were recruited in two cohorts. The first cohort included 1166 men who were aged 54 years as at 1984-1986, and the second cohort included 1516 men aged 42, 48, 54, or 60 years during 1986-1989. This was followed by a 4-year examination round (1991-1993) in which 1038 men from the second cohort $(88 \%$ of the eligible) participated. At the 11-year examination round (1998-2001), all men from the second cohort were invited and 854 men (95\% of the eligible) participated. During the 20-year examination round, all eligible participants from the first and second cohort were invited to the study site. A total of 1241 men (80\% of the eligible) participated. We excluded participants with prevalent T2DM at baseline (162), who had not participated in at least one of the re-examination rounds (881), who had no values for sF (23), and who had high ferritin hereditary hemochromatosis (3), leaving a total of 1613 for the current analysis (Supplementary Figure 1, see section on supplementary data given at the end of this article). The cases of high ferritin hereditary hemochromatosis in our data sets were identified based on Cys282Tyr HFE genotyping. There were 553 subjects for whom there was no value for sTfR. The Research Ethics Committee of Kuopio University has approved the KIHD study and the participants gave their written informed consent to participate.

\section{Data collection}

Details of data collection on anthropometry measurements (20), physical activity, which was assessed using the KIHD 12-Month Leisure-Time Physical Activity Questionnaire (21), blood pressure (22), hypertension medication (22), dyslipidemia medication (22), smoking status, number of cigarettes smoked, duration of smoking in years (23), alcohol consumption (23), and dietary intake of foods and nutrients including dietary iron, using a 4-day food recording (24), have been described earlier. The family history of diabetes was defined as positive if a first-degree relative of the subject had a history of diabetes. T2DM was defined as a self-reported physician-set diagnosis of T2DM and/or fasting plasma glucose $\geq 7.0 \mathrm{mmol} / \mathrm{l}$ (blood glucose $\geq 6.25 \mathrm{mmol} / \mathrm{l}$ ) or 2 -h oral glucose tolerance test plasma glucose $\geq 11.1 \mathrm{mmol} / \mathrm{l}$ (blood glucose $\geq 9.9 \mathrm{mmol} / \mathrm{l}$ ) at any of the study visits and by record linkage to the Social Insurance Institution of Finland register for reimbursement of medicine expenses used for T2DM for the entire study period at the end of the study.

\section{Biomarkers and other measurements}

Subjects visited the study site to give blood samples in the morning hours between 0800 and $1000 \mathrm{~h}$, after an overnight fast and abstinence from alcohol use for 3 days and tobacco smoking for $12 \mathrm{~h}$ before giving the sample. The baseline $\mathrm{sF}$ measurement was assayed from stored serum samples by RIA based on a doubleantibody technique (RIA Amersham International, Amersham, UK), and sTfR concentration was assayed from stored samples by the IDeA Transferrin Receptor Immunoenzymometric Assay (ORION Diagnostica, Espoo, Finland). Detailed descriptions of these markers of body iron stores (23), serum LDL (22), serum HDL (22), serum triglyceride (22), serum C-reactive protein (25), and serum gamma-glutamyl transpeptidase (GGT) (26) have been published earlier. The blood glucose measurements were assessed by the glucose dehydrogenase method (27).

\section{Statistical analyses}

Test of linear trend across quintiles of baseline sF was carried out for relevant characteristics of the study population. Mann-Whitney $U$ test was used to compare the $\mathrm{sF}$ concentration of those who later developed T2DM and those who remained free of T2DM. Multivariableadjusted logistic regression model was used to analyze the association between baseline sF and incident T2DM (Table 1). Multivariable-adjusted Cox proportional hazards regression model was used to analyze the association between baseline sF and incident T2DM (Fig. 1) and also the association between baseline sTfR and incident T2DM (Fig. 2).

The potential confounders in our data that were tested for included age (years); examination date (years); BMI $\left(\mathrm{kg} / \mathrm{m}^{2}\right)$; serum C-reactive protein concentration (mg/l, high sensitivity method); physical activity (conditioning leisure-time sessions per week); smoking (pack years); systolic and diastolic blood pressure

Table 1 Multivariate-adjusted odds ratio for incident type 2 diabetes.

\begin{tabular}{lccc}
\hline Characteristics & $\begin{array}{c}\text { Odds } \\
\text { ratio }\end{array}$ & $\begin{array}{c}\mathbf{9 5 \%} \text { Cl } \\
\text { (low-high) }\end{array}$ & $\begin{array}{c}\boldsymbol{P} \\
\text { value }\end{array}$ \\
\hline Age (years) & 0.99 & $0.96-1.01$ & 0.32 \\
Examination date (years) & 0.94 & $0.86-1.02$ & 0.15 \\
Ferritin (per $100 \mu \mathrm{g} / \mathrm{l})$ & 1.14 & $1.03-1.26$ & 0.009 \\
BMI $\left(\mathrm{kg} / \mathrm{m}^{2}\right.$ ) & 1.08 & $1.01-1.16$ & 0.03 \\
Systolic BP (mmHg) & 1.01 & $1.00-1.02$ & 0.18 \\
Diabetes in family (yes) & 1.85 & $1.41-2.43$ & $<0.001$ \\
Drug for hypertension (yes) & 1.46 & $1.05-2.02$ & 0.02 \\
Drug for dyslipidemia (yes) & 3.71 & $1.07-12.89$ & 0.04 \\
Serum GGT (U/l) & 1.01 & $1.00-1.10$ & 0.02 \\
Serum triglyceride (mmol/l) & 1.13 & $0.97-1.33$ & 0.13 \\
Alcohol intake (g/week) & 1.01 & $1.00-1.03$ & 0.07 \\
Waist circumference (cm) & 1.02 & $1.00-1.05$ & 0.08 \\
Smoking (pack years) & 1.01 & $1.00-1.02$ & 0.17 \\
Total energy intake (kcal/day) & 1.01 & $1.00-1.01$ & 0.14 \\
\hline
\end{tabular}




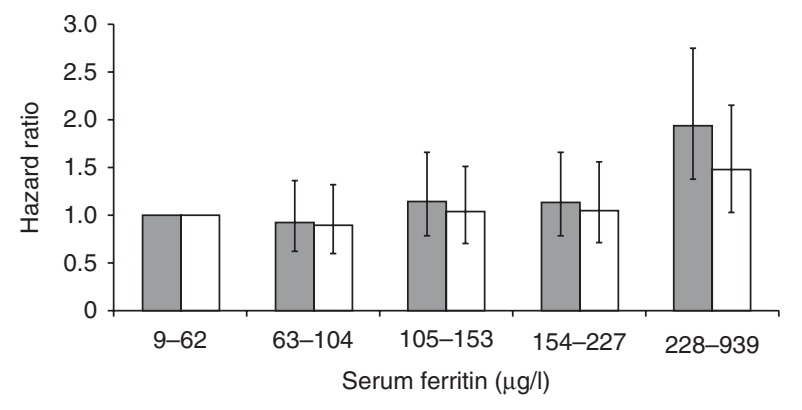

Figure 1 Risk of type 2 diabetes with increasing serum ferritin quintiles. Gray bars represent the age and examination year-adjusted risk. The white bars represent the fully adjusted risk. The lines indicate the $95 \% \mathrm{Cl}$.

(mmHg, mean of six measurements); medication for hypertension (yes, \%); medication for dyslipidemia (yes, $\%$ ); family history of diabetes (yes, \%); serum LDL, HDL, and triglyceride concentrations ( $\mathrm{mmol} / \mathrm{l})$; serum GGT (U/l); alcohol intake (grams of absolute ethanol per week); mean waist circumference $(\mathrm{cm})$; and total daily energy intake (kcal, derived from a 4-day food diary).

The relative risk of incident T2DM per $100 \mu \mathrm{g} / \mathrm{l}$ increase in $\mathrm{sF}$ concentration, adjusting for covariates, was computed as odds ratio (OR) by logistic regression. The final covariate set was defined by the backward stepwise method, $P \leq 0.2$, for removal. The missing values in the continuous covariates were $<5 \%$ and were replaced by the cohort mean.

Tests of linear trend were conducted by assigning the median values for each category of exposure variable and treating those as a single continuous variable. For the tests of quadratic (non-linear) trend, the variable was squared after centering it at median sTfR value. The statistical analyses were performed using SPSS 19 for Windows, and test for statistical significance (at $P<0.05$ ) was two sided.

\section{Results}

The mean age of the subjects was 52.5 years (s.D. 5.7, range 42.0-61.3 years). The mean $\mathrm{sF}$ concentration was $159 \mu \mathrm{g} / \mathrm{l}$ (s.D. 128, range 9-939 $\mu \mathrm{g} / \mathrm{l}$ ) in the whole population. Those with higher $\mathrm{sF}$ within the population were more likely to have higher BMI, higher waist circumference, higher blood pressure, higher dyslipidemia, higher intake of alcohol, lower total daily energy intake, and fewer sessions of leisure-time physical activity per week (Table 2). The subjects in the highest $\mathrm{sF}$ quintile had the highest blood glucose concentration $(4.66 \mathrm{mmol} / \mathrm{l}$ (s.D. 0.48), P-trend $<0.001)$ and the highest serum insulin concentration $(13.28 \mathrm{mU} / \mathrm{l}$ (s.D. 7.19), $P$-trend <0.001) (Table 2).

During the average follow-up time of 16.8 years (27098 person-years), there were 331 cases of incident T2DM among the 1613 men. In the baseline sF quintiles, lowest to highest, we observed $16.0 \%$ (51 in
319 ), $15.8 \%$ (52 in 330), $21.2 \%$ (68 in 320 ), $20.3 \%$ (66 in 324), and 29.3\% (94 in 320) cumulative T2DM cases. At baseline, subjects who later developed T2DM had higher average $\mathrm{sF}$ concentration, $191 \mu \mathrm{g} / \mathrm{l}$ (S.D. 155) vs $151 \mu \mathrm{g} / \mathrm{l}$ (s.D. 119), than in subjects that remained free of T2DM $(P<0.001)$. In the backward conditional logistic regression analysis with all the potential confounders in our data set, an increase of $100 \mu \mathrm{g} / \mathrm{l}$ in $\mathrm{sF}$ corresponded to an average of $14 \%$ increase $(\mathrm{OR}=1.14,95 \%$ CI $1.03-1.26, P=0.009)$ (Table 1) in the risk of developing T2DM.

In the multivariate-adjusted Cox regression model, the subjects in the highest $\mathrm{sF}$ quintile had a statistically significant $50 \%$ increased (hazards ratio $(\mathrm{HR})=1.5$, 95\% CI 1.0-2.2, P-trend $=0.05$ ) risk to develop T2DM during the follow-up, compared with the subjects in the lowest quintile (Fig. 1). Other statistically significant predictors of incident T2DM were BMI, family history of diabetes, hypertension medication, dyslipidemia medication, serum GGT, and alcohol intake (Table 1). A linear increase in the risk of developing T2DM over the normal $\mathrm{sF}$ range $(30-300 \mu \mathrm{g} / \mathrm{l}$ for male) was not observed; rather, variation in the risk was observed with marked increase in the risk of T2DM between the fourth and fifth sF quintiles (Fig. 1).

In the analysis in which sTfR was used in the multivariable-adjusted Cox regression model, the subjects in the third quintile had the least risk $(\mathrm{HR}=0.63$, $95 \%$ CI $0.42-0.97, P=0.04$ ) of developing T2DM when compared with subjects in the lowest quintile (Fig. 2). In the post hoc analysis, we performed a nonlinear trend test that showed a borderline nonlinear trend $(P=0.057)$, suggesting a U-shaped type of association between sTfR and T2DM.

In a subgroup of subjects $(n=1060)$ for whom data were available to compute sTfR to sF ratio (sTfR:sF), those subjects in the lowest quintile had statistically significant highest risk $(\mathrm{HR}=1.75,95 \%$ CI $1.06-2.88$, $P$-trend $=0.17$ ) to develop T2DM in the multivariateadjusted Cox regression model.

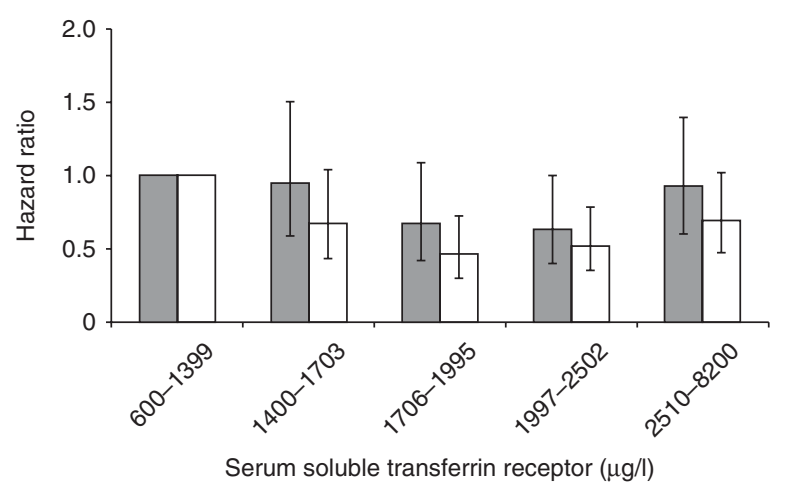

Figure 2 Risk of type 2 diabetes with increasing serum-soluble transferrin receptor quintiles. Gray bars represent the age and examination year-adjusted risk. The white bars represent the fully adjusted risk. The lines indicate the $95 \% \mathrm{Cl}$. 
Table 2 Baseline characteristics of the study population of 1613 eastern Finnish men in the Kuopio Ischemic Heart Disease Risk Factor study, 1984-1989.

\begin{tabular}{|c|c|c|c|c|c|c|}
\hline \multirow[b]{2}{*}{ Characteristics } & \multicolumn{6}{|c|}{ Serum ferritin quintiles $(\mu \mathrm{g} / \mathrm{l})$} \\
\hline & $1(9-62)$ & $2(63-104)$ & $3(105-153)$ & $4(154-227)$ & $5(228-939)$ & $P$-trend \\
\hline Blood glucose (mmol/l) & $4.50 \pm 0.45$ & $4.48 \pm 0.44$ & $4.56 \pm 0.44$ & $4.58 \pm 0.47$ & $4.66 \pm 0.48$ & $<0.001$ \\
\hline Serum insulin (mU/l) & $9.70 \pm 4.70$ & $9.44 \pm 4.32$ & $10.46 \pm 6.86$ & $11.03 \pm 5.59$ & $13.28 \pm 7.19$ & $<0.001$ \\
\hline Age (years) & $53 \pm 5.5$ & $53 \pm 5.6$ & $53 \pm 5.6$ & $52 \pm 6.0$ & $51 \pm 5.7$ & $<0.001$ \\
\hline BMI $\left(\mathrm{kg} / \mathrm{m}^{2}\right)$ & $25.7 \pm 3.0$ & $26.1 \pm 3.0$ & $26.6 \pm 3.2$ & $26.9 \pm 3.0$ & $27.9 \pm 3.4$ & $<0.001$ \\
\hline Smoking (pack years) & $7.0 \pm 15.1$ & $6.4 \pm 14.3$ & $7.1 \pm 14.2$ & $5.6 \pm 13.3$ & $5.4 \pm 12.3$ & 0.11 \\
\hline Systolic BP (mmHg) & $130 \pm 15$ & $131 \pm 16$ & $132 \pm 16$ & $132 \pm 16$ & $135 \pm 15$ & $<0.001$ \\
\hline Diastolic BP $(\mathrm{mmHg})$ & $86 \pm 10$ & $87 \pm 10$ & $87 \pm 9$ & $88 \pm 10$ & $90 \pm 10$ & $<0.001$ \\
\hline Drug for high BP (yes \%) & 12.9 & $19 . \overline{7}$ & 25 & $18 . \overline{5}$ & $1 \overline{9} .4$ & 0.09 \\
\hline Drug for dyslipidemia (yes \%) & 1.6 & 0.9 & 0.9 & 0.3 & 0 & 0.01 \\
\hline Serum C-reactive protein (mg/l) & $1.9 \pm 3.0$ & $1.7 \pm 2.4$ & $2.5 \pm 5.8$ & $2.3 \pm 3.5$ & $2.2 \pm 4.6$ & 0.09 \\
\hline Serum GGT (U/I) & $23.2 \pm 26.8$ & $21.6 \pm 13.4$ & $24.4 \pm 17$ & $27.4 \pm 19.1$ & $35.3 \pm 31$ & $<0.001$ \\
\hline Serum LDL-cholesterol (mmol/l) & $3.86 \pm 1.00$ & $4.02 \pm 0.97$ & $3.97 \pm 1.01$ & $3.92 \pm 0.97$ & $3.96 \pm 0.89$ & 0.54 \\
\hline Serum HDL-cholesterol (mmol/l) & $1.34 \pm 0.31$ & $1.34 \pm 0.32$ & $1.30 \pm 0.28$ & $1.27 \pm 0.29$ & $1.27 \pm 0.31$ & $<0.001$ \\
\hline Serum triglyceride $(\mathrm{mmol} / \mathrm{l})$ & $1.15 \pm 0.59$ & $1.23 \pm 0.63$ & $1.24 \pm 0.67$ & $1.33 \pm 0.91$ & $1.55 \pm 1.03$ & $<0.001$ \\
\hline Alcohol intake (g/week) & $41.4 \pm 70.3$ & $56.4 \pm 92.3$ & $64.6 \pm 102.9$ & $70.7 \pm 99.3$ & $106.0 \pm 164.6$ & $<0.001$ \\
\hline Total energy intake (kcal/day) & $2433 \pm 624$ & $2447 \pm 566$ & $2416 \pm 684$ & $2336 \pm 609$ & $2285 \pm 588$ & $<0.001$ \\
\hline Waist circumference $(\mathrm{cm})$ & $87.9 \pm 8.3$ & $89.0 \pm 8.2$ & $89.9 \pm 8.7$ & $90.6 \pm 8.3$ & $93.3 \pm 8.9$ & $<0.001$ \\
\hline $\begin{array}{l}\text { Leisure-time physical activity } \\
\text { (sessions/week) }\end{array}$ & $143 \pm 151$ & $131 \pm 132$ & $146 \pm 145$ & $117 \pm 125$ & $119 \pm 127$ & 0.009 \\
\hline${ }^{\mathrm{a}} \mathrm{sTfR}(\mu \mathrm{g} / \mathrm{l})$ & $1914 \pm 606$ & $1911 \pm 723$ & $1891 \pm 633$ & $1952 \pm 708$ & $2023 \pm 712$ & 0.07 \\
\hline${ }^{a} \mathrm{STfR} / \mathrm{sF}$ & $48.4 \pm 19.5$ & $23.6 \pm 9.9$ & $15.0 \pm 5.3$ & $10.6 \pm 4.0$ & $6.3 \pm 2.6$ & $<0.001$ \\
\hline
\end{tabular}

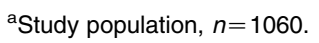

\section{Discussion}

In this prospective cohort study, higher body iron stores, as assessed by the $\mathrm{sF}$ concentration, was associated with increased risk of T2DM. However, iron depletion toward mild iron deficiency, as assessed by the sTfR concentration, was not protective against T2DM. When observed over the wide $\mathrm{sF}$ range, there appeared to be little variation in the risk of T2DM, with marked increase in the risk only between the fourth and fifth sF quintiles (median values of 185 and $310 \mu \mathrm{g} / \mathrm{l}$ respectively) (Fig. 1). After adjusting for confounders, we observed that there seemed to be a U-shaped association between sTfR concentration and the risk of T2DM, with the lowest risk at the middle quintile.

In overt iron overload such as in hereditary hemochromatosis, iron accumulation deteriorates glucose homeostasis and results in T2DM (28). Also, in non-iron overload disorders, accumulating epidemiological studies $(10,12,13,14,15,16)$ have found supportive evidence for iron-T2DM hypothesis. In a recent meta-analysis of six epidemiological studies that investigated the association between body iron stores and the risk of T2DM, a pooled relative risk for T2DM in an individual with the highest vs the lowest $\mathrm{sF}$ concentrations was 1.70 (19).

Still, none of these studies suggested any range within which the body iron stores should be maintained, and most of them concluded on mild-to-moderate elevated body iron stores as a risk factor for T2DM. In line with these studies, we also found that for every $100 \mu \mathrm{g} / \mathrm{l}$ increase in sF, there was an average 14\% increase in the risk of developing T2DM.

The normal range of sF could vary between laboratories, but in males, $30-300 \mu \mathrm{g} / \mathrm{l}$ is the common reference range. We observed from our data that the risk of developing T2DM begins to be markedly increased at around $185 \mu \mathrm{g} / \mathrm{l}$ (the median of the fourth quintile of sF) (Fig. 1). Our data further suggested that the risk of T2DM is the least at the third quintile of sTfR (Fig. 2). On the basis of findings recorded in Figs 1 and 2, a rule of thumb safe range for body iron with regard to T2DM risk could be 30-200 $\mu \mathrm{g} / \mathrm{l}$ of sF. Indirect supportive evidence was observed in a cross-sectional study conducted by Fernandez-Real et al. (29) in Spain with 181 middle-aged healthy men, in which they investigated the relationship between iron stores and insulin sensitivity between blood donors and non-donors. They showed that frequent blood donors, who had the mean $\mathrm{sF}$ concentration maintained at $101.5 \mu \mathrm{g} / \mathrm{l}$, had increased insulin sensitivity and decreased insulin secretion compared with non-donors who had the mean sF concentration of $162 \mu \mathrm{g} / \mathrm{l}$. An interventional study by Facchini (30) assessed the effect of lowering of body iron stores by phlebotomy on plasma glucose and insulin concentration. He found that lowering $\mathrm{sF}$ from 75 to $38 \mu \mathrm{g} / \mathrm{l}$ led to 37 and $19 \%$ reduction in $2-\mathrm{h}$ plasma insulin and glucose concentrations respectively in ten healthy individuals. Also, a few controlled interventional studies have demonstrated the positive effect of iron depletion on insulin resistance $(31,32)$, which could be more pronounced in subjects with 
elevated baseline $\mathrm{sF}$ than in those with relatively normal baseline $s F(31)$. These studies $(29,30)$ suggest that maintaining the $\mathrm{sF}$ below high normal could possibly prove useful in reducing the prevalence of T2DM.

In the analysis in our data using sTfR, we observed that the subjects in the third, fourth, and fifth quintiles of sTfR had 37,33 , and $6 \%$ respectively reduction in the risk of developing T2DM when compared with subjects in the lowest quintile. It was speculated that if iron excess could increase the risk of T2DM, then iron depletion toward iron deficiency should induce the reverse phenomenon of protection (30). This of course partially holds within $\mathrm{sF}$ reference range as demonstrated in our study, but further depletion of body iron stores nearing iron deficiency, using sTfR as the indicator, appeared not to offer additional protection against T2DM. Although sTfR assay is of valuable clinical importance because the concentration does not increase in anemia of chronic inflammation but rather in iron-deficient erythropoiesis and iron deficiency anemia, its concentration may also increase in conditions or processes that stimulate erythropoiesis, such as hemolytic anemia, erythropoietin therapy, and erythroid dysplasia or hyperplasia (11).

Our finding is supported by the results of a prospective study among 54 non-diabetic premenopausal women that investigated the effect of iron deficiency on insulin resistance (33). After treatment with oral iron preparation, a statistically significant decrease in fasting insulin concentrations following the anemia treatment was observed in younger women $(<40$ years) and in women with low BMI $\left(<27 \mathrm{~kg} / \mathrm{m}^{2}\right)$. Also, Ford et al. (34) found in a cross-sectional study of 8296 adults who participated in the National Health and Nutrition Examination Survey (NHANES) that iron deficiency tends to increase $\mathrm{HbA1c}$ level rather than decreasing it. In addition, Shakoury-Elizeh et al. (35) showed that iron deficiency leads to impairment in glucose metabolism by altering glucose storage.

It is not far-fetched that iron-deficient cells will exhibit depletion of iron enzymes and thus affect processes in which iron serves as a cofactor. Every cell in the body, including the hepatocytes, needs a minimum level of iron, excess of which on the other hand is toxic to the cell. Thus, the optimal range needs to be clearly established.

The mechanism behind the association between body iron stores and T2DM is still not known in detail, but oxidative damage by excess iron stores in the liver, pancreas, and the muscle has been reported $(2,3)$, with subsequent insulin resistance $(4,5,8)$. Also, the oxidative damage of the lipid cell membrane may be a predisposing factor for decreased cellular glucose uptake (36). Others include iron-regulated adiponectin and iron-mediated adipocyte insulin resistance $(37,38)$.

The prospective design and the long follow-up are the strengths of our study. A limitation in this study is the data on biomarkers of body iron stores that were from a single blood sample, which may have changed during the follow-up and may not thus accurately reflect the exposure level during the relevant time period. Because of the large proportion of missing data in the sTfR concentration $\left(n_{\mathrm{m}}=553\right)$ in the studied population, we could not compute for all study participants the sTfR/sF, which has been proposed as the preferred measure of body iron stores by some authors (39). Over $40 \%$ of the subjects who later developed T2DM were lost in the subgroup analysis, reducing the power to find a significant trend in the multivariate-adjusted Cox regression model. It is known that elevated $\mathrm{sF}$ can be found in other conditions that are risk factors of T2DM, such as obesity, metabolic syndrome, inflammation, and liver disease. Thus, we extensively adjusted our results for these conditions by controlling for BMI, waist circumference, serum GGT, serum C-reactive protein, alcohol consumption, and medications for hypertension and dyslipidemia. However, we cannot completely exclude the effect of residual confounding. The relatively few incident cases of T2DM within the normal $\mathrm{sF}$ range did not allow for subgroup analyses strictly within this range.

In conclusion, accumulating epidemiological findings suggest elevated body iron stores as a risk factor for developing T2DM, but the safety range is less known. Our study has provided additional knowledge about the likely threshold of $\mathrm{sF}$ at which the risk of T2DM becomes marked, the sTfR range within which the risk of T2DM is expected to be the least, and a rule of thumb safe range of $\mathrm{sF}$ with regard to T2DM risk. However, these findings would require more observational studies reporting the likely thresholds in their data as well.

\section{Supplementary data}

This is linked to the online version of the paper at http://dx.doi.org/10. 1530/EJE-13-0145.

\section{Declaration of interest}

The authors declare that there is no conflict of interest that could be perceived as prejudicing the impartiality of the research reported.

\section{Funding}

This work was supported by the Academy of Finland Research grant no. 128168 to T-P Tuomainen and Juho Vainio Foundation Research grant no. 201310093 to A Aregbesola.

\section{Author contribution statement}

A Aregbesola, S Voutilainen, J K Virtanen, and T-P Tuomainen were involved in the conception and design of the study including quality assurance and control. A Aregbesola, T-P Tuomainen, $\mathrm{S}$ Voutilainen, and J K Virtanen were involved in the acquisition of data. A Aregbesola, S Voutilainen, J K Virtanen, J Mursu, and T-P Tuomainen were involved in literature search, material and methods, and study analytical concepts. A Aregbesola, T-P Tuomainen, J K Virtanen, S Voutilainen, and J Mursu were involved in analysis and interpretation of data. A Aregbesola, S Voutilainen, 
J K Virtanen, J Mursu, and T-P Tuomainen were involved in discussion section. A Aregbesola, S Voutilainen, J K Virtanen, J Mursu, and T-P Tuomainen were involved in final review and approval of the version to be published.

\section{Acknowledgements}

The authors express their gratitude to the staff of Institute of Public Health and Clinical Nutrition for data collection.

\section{References}

1 Moczulski DK, Grzeszczak W \& Gawlik B. Role of hemochromatosis $\mathrm{C} 282 \mathrm{Y}$ and H63D mutations in HFE gene in development of type 2 diabetes and diabetic nephropathy. Diabetes Care 2001 24 1187-1191. (doi:10.2337/diacare.24.7.1187)

2 Oberley LW. Free radicals and diabetes. Free Radical Biology \& Medicine 19885 113-124. (doi:10.1016/0891-5849(88)90036-6)

3 Drews G, Krippeit-Drews P \& Dufer M. Oxidative stress and $\beta$-cell dysfunction. Pflügers Archiv 2010460 703-718. (doi:10.1007/ s00424-010-0862-9)

4 Opara EC. Oxidative stress, micronutrients, diabetes mellitus and its complications. Journal of the Royal Society for the Promotion of Health $2002 \mathbf{1 2 2}$ 28-34. (doi:10.1177/14664240021 2200112)

5 Sharifi F, Nasab NM \& Zadeh HJ. Elevated serum ferritin concentrations in prediabetic subjects. Diabetes \& Vascular Disease Research 20085 15-18. (doi:10.3132/dvdr.2008.003)

6 Syrovatka P, Kraml P, Potockova J, Fialova L, Vejrazka M, Crkovska J \& Andel M. Relationship between increased body iron stores, oxidative stress and insulin resistance in healthy men. Annals of Nutrition and Metabolism 200954 268-274. (doi:10.1159/000229507)

7 Suarez-Ortegon MF, Arbelaez A, Mosquera M, Mendez F \& Aguilar-de Plata C. Body iron stores as predictors of insulin resistance in apparently healthy urban Colombian men. Biological Trace Element Research 2012145 283-285. (doi:10.1007/ s12011-011-9192-9)

8 Dongiovanni P, Fracanzani AL, Fargion S \& Valenti L. Iron in fatty liver and in the metabolic syndrome: a promising therapeutic target. Journal of Hepatology 201155 920-932. (doi:10.1016/ j.jhep.2011.05.008)

9 Skikne BS, Flowers CH \& Cook JD. Serum transferrin receptor: a quantitative measure of tissue iron deficiency. Blood $1990 \mathbf{7 5}$ 1870-1876.

10 Forouhi NG, Harding AH, Allison M, Sandhu MS, Welch A, Luben R, Bingham S, Khaw KT \& Wareham NJ. Elevated serum ferritin levels predict new-onset type 2 diabetes: results from the EPIC-Norfolk prospective study. Diabetologia 200750 949-956. (doi:10.1007/s00125-007-0604-5)

11 Skikne BS. Serum transferrin receptor. American Journal of Hematology 200883 872-875. (doi:10.1002/ajh.21279)

12 Salonen JT, Tuomainen TP, Nyyssonen K, Lakka HM \& Punnonen K. Relation between iron stores and non-insulin dependent diabetes in men: case-control study. BMJ $1998 \mathbf{3 1 7}$ 727. (doi:10.1136/bmj.317.7160.727)

13 Jiang R, Manson JE, Meigs JB, Ma J, Rifai N \& Hu FB. Body iron stores in relation to risk of type 2 diabetes in apparently healthy women. Journal of the American Medical Association 2004291 711-717. (doi:10.1001/jama.291.6.711)

14 Fumeron F, Pean F, Driss F, Balkau B, Tichet J, Marre M \& Grandchamp B. Ferritin and transferrin are both predictive of the onset of hyperglycemia in men and women over 3 years: the data from an epidemiological study on the Insulin Resistance Syndrome (DESIR) study. Diabetes Care 200629 2090-2094. (doi:10.2337/ dc06-0093)

15 Jehn ML, Guallar E, Clark JM, Couper D, Duncan BB, Ballantyne CM, Hoogeveen RC, Harris ZL \& Pankow JS.
A prospective study of plasma ferritin level and incident diabetes: the Atherosclerosis Risk in Communities (ARIC) Study. American Journal of Epidemiology 2007165 1047-1054. (doi:10.1093/aje/ kwk093)

16 Montonen J, Boeing H, Steffen A, Lehmann R, Fritsche A, Joost HG, Schulze MB \& Pischon T. Body iron stores and risk of type 2 diabetes: results from the European Prospective Investigation into Cancer and Nutrition (EPIC)-Potsdam study. Diabetologia 201255 2613-2621. (doi:10.1007/s00125-0122633-y)

17 Kolberg JA, Jorgensen T, Gerwien RW, Hamren S, McKenna MP, Moler E, Rowe MW, Urdea MS, Xu XM, Hansen $\mathrm{T}$ et al. Development of a type 2 diabetes risk model from a panel of serum biomarkers from the Inter99 cohort. Diabetes Care 200932 1207-1212. (doi:10.2337/dc08-1935)

18 Rajpathak SN, Wylie-Rosett J, Gunter MJ, Negassa A, Kabat GC, Rohan TE \& Crandall J. Biomarkers of body iron stores and risk of developing type 2 diabetes. Diabetes, Obesity \& Metabolism 200911 472-479. (doi:10.1111/j.1463-1326.2008.00985.x)

19 Bao W, Rong Y, Rong S \& Liu L. Dietary iron intake, body iron stores, and the risk of type 2 diabetes: a systematic review and meta-analysis. BMC Medicine 201210 119. (doi:10.1186/17417015-10-119)

20 Salonen JT. Is there a continuing need for longitudinal epidemiologic research? The Kuopio Ischaemic Heart Disease Risk Factor Study. Annals of Clinical Research 198820 46-50.

21 Lakka TA, Venalainen JM, Rauramaa R, Salonen R, Tuomilehto J \& Salonen JT. Relation of leisure-time physical activity and cardiorespiratory fitness to the risk of acute myocardial infarction. New England Journal of Medicine 1994330 1549-1554. (doi:10.1056/NEJM199406023302201)

22 Salonen JT, Nyyssonen K, Korpela H, Tuomilehto J, Seppanen R \& Salonen R. High stored iron levels are associated with excess risk of myocardial infarction in eastern Finnish men. Circulation 199286 803-811. (doi:10.1161/01.CIR.86.3.803)

23 Tuomainen TP, Punnonen K, Nyyssonen K \& Salonen JT. Association between body iron stores and the risk of acute myocardial infarction in men. Circulation 199897 1461-1466. (doi:10.1161/01.CIR.97.15.1461)

24 Voutilainen S, Rissanen TH, Virtanen J, Lakka TA, Salonen JT \& Kuopio Ischemic Heart Disease Risk Factor Study. Low dietary folate intake is associated with an excess incidence of acute coronary events: The Kuopio Ischemic Heart Disease Risk Factor Study. Circulation 2001103 2674-2680. (doi:10.1161/01.CIR. 103.22.2674)

25 Virtanen JK, Nurmi T, Voutilainen S, Mursu J \& Tuomainen TP. Association of serum 25-hydroxyvitamin D with the risk of death in a general older population in Finland. European Journal of Nutrition 201150 305-312. (doi:10.1007/s00394010-0138-3)

26 Salonen JT. Liver damage and protective effect of high density lipoprotein cholesterol. BMJ 2003327 1082-1083. (doi:10.1136/ bmj.327.7423.1082)

27 Tuomainen TP, Nyyssonen K, Salonen R, Tervahauta A, Korpela H, Lakka T, Kaplan GA \& Salonen JT. Body iron stores are associated with serum insulin and blood glucose concentrations. Population study in 1,013 eastern Finnish men. Diabetes Care 199720 426-428. (doi:10.2337/diacare.20.3.426)

28 Halsall DJ, McFarlane I, Luan J, Cox TM \& Wareham NJ. Typical type 2 diabetes mellitus and HFE gene mutations: a populationbased case-control study. Human Molecular Genetics 200312 1361-1365. (doi:10.1093/hmg/ddg149)

29 Fernandez-Real JM, Lopez-Bermejo A \& Ricart W. Iron stores, blood donation, and insulin sensitivity and secretion. Clinical Chemistry 200551 1201-1205. (doi:10.1373/clinchem.2004. 046847)

30 Facchini FS. Effect of phlebotomy on plasma glucose and insulin concentrations. Diabetes Care 199821 2190. (doi:10.2337/ diacare.21.12.2190b)

31 Valenti L, Fracanzani AL, Dongiovanni P, Bugianesi E, Marchesini G, Manzini P, Vanni E \& Fargion S. Iron depletion by phlebotomy 
improves insulin resistance in patients with nonalcoholic fatty liver disease and hyperferritinemia: evidence from a case-control study. American Journal of Gastroenterology 2007102 1251-1258. (doi:10.1111/j.1572-0241.2007.01192.x)

32 Equitani F, Fernandez-Real JM, Menichella G, Koch M, Calvani M, Nobili V, Mingrone G \& Manco M. Bloodletting ameliorates insulin sensitivity and secretion in parallel to reducing liver iron in carriers of HFE gene mutations. Diabetes Care 200831 3-8. (doi:10.2337/dc07-0939)

33 Ozdemir A, Sevinc C, Selamet U, Kamaci B \& Atalay S. Ageand body mass index-dependent relationship between correction of iron deficiency anemia and insulin resistance in non-diabetic premenopausal women. Annals of Saudi Medicine 200727 356-361. (doi:10.4103/0256-4947.51476)

34 Ford ES, Cowie CC, Li C, Handelsman Y \& Bloomgarden ZT. Irondeficiency anemia, non-iron-deficiency anemia and HbA1c among adults in the US. Journal of Diabetes 20113 67-73. (doi:10.1111/ j.1753-0407.2010.00100.x)

35 Shakoury-Elizeh M, Protchenko O, Berger A, Cox J, Gable K, Dunn TM, Prinz WA, Bard M \& Philpott CC. Metabolic response to iron deficiency in Saccharomyces cerevisiae. Journal of Biological Chemistry 2010285 14823-14833. (doi:10.1074/jbc.M109.091710)
36 Opara EC. Role of oxidative stress in the etiology of type 2 diabetes and the effect of antioxidant supplementation on glycemic control. Journal of Investigative Medicine 200452 19-23.

37 Gabrielsen JS, Gao Y, Simcox JA, Huang J, Thorup D, Jones D, Cooksey RC, Gabrielsen D, Adams TD, Hunt SC et al. Adipocyte iron regulates adiponectin and insulin sensitivity. Journal of Clinical Investigation $2012 \mathbf{1 2 2}$ 3529-3540. (doi:10.1172/ JCI44421)

38 Wlazlo N, van Greevenbroek MM, Ferreira I, Jansen EH, Feskens EJ, van der Kallen CJ, Schalkwijk CG, Bravenboer B \& Stehouwer CD. Iron metabolism is associated with adipocyte insulin resistance and plasma adiponectin: the Cohort on Diabetes and Atherosclerosis Maastricht (CODAM) study. Diabetes Care 201336 309-315. (doi:10.2337/dc12-0505)

39 Punnonen K, Irjala K \& Rajamaki A. Serum transferrin receptor and its ratio to serum ferritin in the diagnosis of iron deficiency. Blood 199789 1052-1057.

Received 19 February 2013

Revised version received 22 May 2013

Accepted 28 May 2013 